\title{
Application of an Integrated Methodology for Propulsion and Airframe Control Design to a STOVL Aircraft
}

Sanjay Garg

National Aeronautics and Space Administration

Lewis Research Center

Cleveland, Ohio

and

Duane Mattern

NYMA, Inc.

Engineering Services Division

Brook Park, Ohio

Prepared for the

Guidance, Navigation and Control Conference

sponsored by the American Institute of Aeronautics and Astronautics

Scottsdale, Arizona, August 1-3, 1994

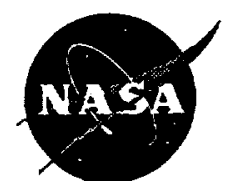

National Aeronautics and Space Administration

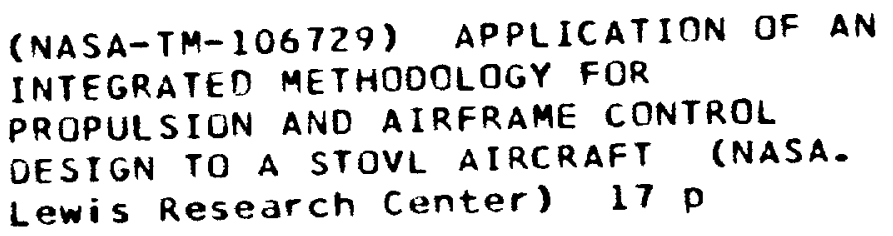


. 
Application of an Integrated Methodology for Propulsion and Airframe Control Design to a STOVL Aircraft

\author{
Sanjay Garg \\ NASA Lewis Research Center \\ 21000 Brookpark Road, MS 77-1 \\ Cleveland, OH 44135
}

\author{
Duane Matter". \\ NYMA Inc., LeRC Group \\ 21000 Brookpark Road, MS 77-1 \\ Cleveland, $\mathrm{OH} 44135$
}

\begin{abstract}
An advanced methodology for Integrated Flight Propulsion Control (IFPC) design for future aircraft, which will use propulsion system generated forces and moments for enhanced maneuver capabilities, is briefly described. This methodology has the potential to address in a systematic manner the coupling between the airframe and the propulsion subsystems typical of such enhanced maneuverability aircraft. Application of the methodology to a Short Take-Off Vertical Landing (STOVL) aircraft in the landing approach to hover transition flight phase is presented with brief description of the various steps in the IFPC design methodology. The details of the individual design steps have been described in previous publications and the objective of this paper is to focus on how the components of the control system designed at each step integrate into the overall IFPC system. The full nonlinear IFPC system was evaluated extensively in nonreal-time simulations as well as piloted simulations. Results from the nonreal-time evaluations are presented in this paper. Lessons learned from this application study are summarized in terms of areas of potential improvements in the STOVL IFPC design as well as identification of technology development areas to enhance the applicability of the proposed design methodology.
\end{abstract}

\section{Introduction}

The trend in future military fighter/tactical aircraft design is towards aircraft with new/enhanced maneuver capabilities such as Short Take-Off and Vertical Landing (STOVL) and high angle of attack performance. An integrated flight/propulsion control (IFPC) system is required in order to obtain these enhanced capabilities with reasonable pilot workload. An integrated approach to control design is then necessary to achieve an effective IFPC system. Two very different approaches to IFPC design that have appeared in the recent literature are a centralized Linear Quadratic Gaussian - Loop Transfer Recovery (LQG/LTR) based approach [1] and a decentralized. hierarchical approach using Linear Quadratic Regulator (LQR) based explicit model-following for control synthesis [2]. These methodologies were evaluated in Refs. [3] and [4], respectively, to assess their strengths and weaknesses as part of a STOVL IFPC program at NASA (National Aeronautics and Space Administration) Lewis Research Center. Two contracted efforts on STOVL IFPC design also evaluated the partitioned approach to integrated control design (Refs. $[5,6]$ ).

Based on the experience gained from these studies an IFPC design methodology called IMPAC, Integrated Methodology for Propulsion and Airframe Control, was developed at NASA Lewis [Ref. 7]. The significant features of the IMPAC methodology are the design of a centralized controller considering the airframe and propulsion subsystem as one integrated system and the partitioning of the centralized controller into decentralized subsystem controllers (subcontrollers) with a intercoupling structure suitable for state-of-the-art IFPC implementation. Here partitioning means approximating the high order centralized controller with two or more lower order subcontrollers which closely match the closed-loop performance and robustness properties of the centralized controller. The centralized control design accounts for all the subsystem interactions in the design stage and the partitioning results in easy to implement subcontrollers that allow for independent subsystem validation. Thus the IMPAC approach strives to combine the best aspects of the two integrated control design approaches developed previously.

\footnotetext{
- Cuntrols Engineer. Associated Fellow AlAA

* Engineter
} 
The objective of this paper is to demonstrate the steps in the IMPAC approach by application to a STOVL aircraft. In the following, the IMPAC approach is first briefly described followed by a description of the airframe and propulsion systems of the STOVL aircraft being studied. The flight phase considered in this study is the decelerating transition during approach to hover landing. During this flight phase, the control of the aircraft is transitioning from aerodynamic control surfaces (wing bome flight) to propulsion system generated forces and moments (powered lift). The IFPC design for the STOVL vehicle in the transition flight phase is then presented by briefly describing the significant aspects of applying each of the IMPAC design steps. Finally, results are presented from a nonlinear closed-loop simulation evaluation of the integrated system for typical pilot control tasks in the transition flight phase.

\section{IMPAC Design Approach}

A flowchart of the IMPAC design approach is shown in Fig. 1. The major IMPAC design steps are (1) Generation of integrated airframe/engine models for control design; (2) Centralized control design considering the airframe and engine system as an integrated system; (3) Partitioning of the centralized controller into separate airframe and engine subcontrollers; (4) Operational flight envelope expansion through scheduling of the partitioned subcontrollers; (5) Nonlinear design such as incorporation of limit logic for operational safety; and (6) Full system controller assembly and evaluation. These design steps are briefly described in the following. A detailed description of the methodology is available in Ref. [7].

Given that integrated, nonlinear dynamic models for the system are available, the first task in the IMPAC design methodology involves generation of linear dynamic models to be used for control law synthesis (Block 1). These control design models are, in general, traditional linear perturbation models of the system taken at various operating points. An important issue in a centralized linear IFPC design approach is how nonlinearities of subsystems (e.g., propulsion system) will effect the validity of the centralized linear control law synthesis. Therefore, some "conditioning" of the control design models, based on nonlinear effects and control design requirements, will be required to obtain state-space dynamic models of the integrated system that will allow a "realistic" centralized control design. The model "conditioning" will be discussed in more detail later in the paper.

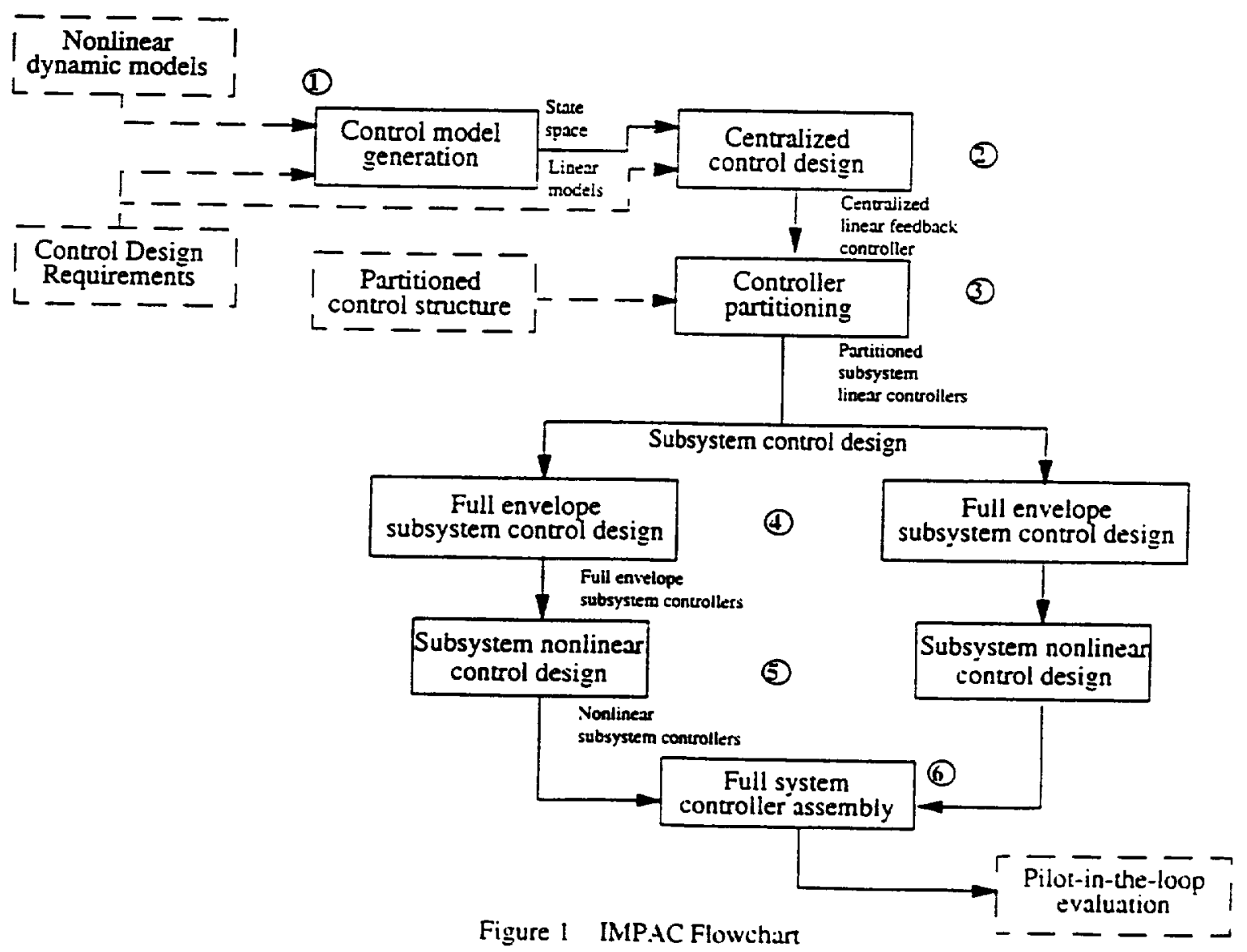


The centralized control design process (Block 2) uses the full system state-space linear control design models previously developed and is based on available multivariable linear control design techniques that have the capability to meet the IFPC requirements, for example $H_{\infty}$ based control synthesis techniques [8]. Design criteria formulated from system performance requirements and system open-loop dynamic studies provide the necessary control design specifications (e.g., frequency or time dependent weighting factors) for the chosen linear design technique. Because the linear control law synthesis tool may result in a high order centralized controller, controller order reduction may be performed at this point in the method. The result of this process is an operating point specific, centralized linear feedback controller for the integrated system.

Once an acceptable centralized controller is designed, it is partitioned into decentralized subcontrollers (Block 3) using mathematical techniques that have been developed (Ref. [9]). The controller partitioning task requires that a candidate control structure for the partitioned system be specified. For example, for the IFPC probiem the assumed control structure is hierarchical with the airfame (flight) control partition exercising some authority over the propulsion control partition. Closed-loop performance and robustness comparisons between the centralized and partitioned linear controllers are made to validate the partitioning results as well as acceptability of the chosen decentralized control structure. The result of the controller partitioning task is a set of linear subcontrollers which match the performance and robustness characteristics of the centralized controller to a specified tolerance.

After completion of the operating point specific linear partitioned subsystem control design, detailed individual subsystem nonlinear control design must be performed. The first step in the nonlinear control design involves extension of the individual subsystem controllers to full envelope operation (Block 4) as defined by the system requirements. Typically this would involve gain scheduling of individual operating point subcontrollers to account for parameter variations due to change in operating conditions. It is envisioned that use of modem robust control synthesis tools to perform the linear control design tasks will reduce the complexity of controller scheduling.

The second subsystem nonlinear control design task (Block 5) involves accounting for the effects of any additional subsystem nonlinearities such as propuision system safery limits. For example, the propulsion system would require exhaust nozzle area control limit logic to ensure that engine surge margins are maintained. After the appropriate nonlinear control loops have been designed, the subcontrollers can be validated using the subsystem dynamic models. The result of this task is the nonlinear limit and accommodation logic to be added to the full envelope subsystem controllers.

The final task in the IMPAC design approach is reassembly of the full envelope, nonlinear subsystem controllers to form the closed-loop integrated system. Evaluations of the final IFPC design can then be performed using nonrealtime simulations as well as pilot-in-the-loop (PITL) simulations. These evaluations would test the actual system performance (e.g., handling qualities) against the desired system performance specifications.

As with any design process, achieving acceptable control design using the IMPAC methodology will involve iterations through the various design steps. However, the strength of the IMPAC approach is that it considers the complete integrated system at each design step and provides the designer the means to systematically assess the level of integrated system performance degradation in going from one step to the other. The control designer can then make some "intelligent" trade-offs between controller complexity and achieved performance at each design step, thus reducing the number and severity of the design iterations.

\section{Vehicle Model}

The vehicle considered in this study is representative of a conceptual delta winged, ejector configured, supersonic STOVL airframe powered by a two-spool turbofan engine [10]. The aircraft is equipped with the following control effectors: left and right elevons used collectively as elevator and differentially as ailerons; rudder; ejectors to provide propulsive lift at low speeds and hover; a 2D-CD (two dimensional convergent-divergent) vectoring aft nozzle; a vectoring ventral nozzle for pitch control and lift augmentation during transition; and jet Reaction Control Systems (RCS) for pitch, roll and yaw control during transition and hover. A schematic diagram of the aircraft. referred to as the E-7D, with relative location of the various control effectors mentioned above is shown in Fig. 2. Engine compressor bleed flow is used for the RCS thrusters and the mixed engine flow is used as the primary ejector flow.

An integrated simulation of the open-loop aircraft dynamics was built-up in a computer aided control system design and analysis graphical environment using separate models of the various subsystems. The major components of this integrated model are an airframe six degree-of-freedom (dof) simulation and a component level model (c/m) 


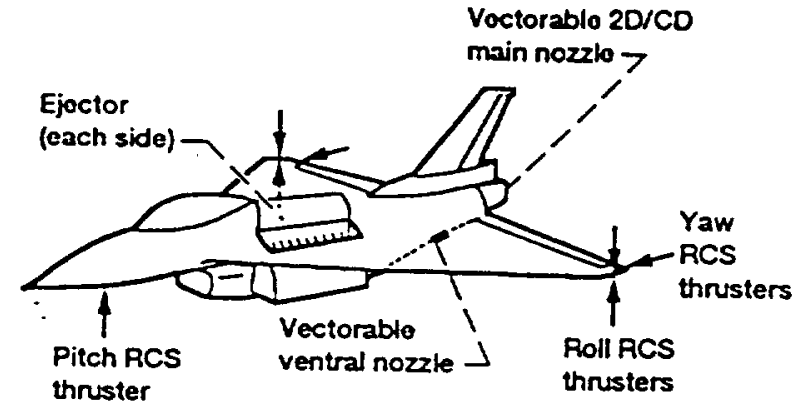

Figure 2 Control Effectors for E-7D Aircraft

simulation of the propulsion system (Refs. $[10,11])$. The airframe six dof simulation uses airframe stability derivatives derived from wind tunnel test data and a simplified "actuator" type model of the propulsion system performance. The propulsion system simulation is a component level model of a turbofan engine which includes inlet and nozzle effects. The other components of the integrated simulation are: the Reaction Control System (RCS) model which generates the RCS thrust for the 5 thrusters based on the RCS nozzle areas and thrust augmentation effects due to aircraft motion; the airframe, engine and RCS actuator dynamic models which include position and rate limits; airframe and engine sensor dynamics; and the gust and environment models.

It is worthwhile here to discuss some of the interactions between the various modules that make up the integrated model. The coupling from the propulsion system to the airframe is through the axial and vertical components of the gross thrusts from the aft and ventral nozzles, the left and right ejector thrusts, and the inlet ram drag effects. The coupling from the airframe to the engine is through Mach No. (M) and altitude (h) which model the inlet flow conditions. Furthermore, the bleed flow demand (WB3) by the RCS, which is used to control the aircraft at low speeds, acts as a disturbance on the engine thus adding another level of coupling from the airframe to the propulsion system.

\section{IMPAC Based STOVL IFPC Design}

\section{Control Model Generation}

Linear integrated airframeiengine models for control design and evaluation were generated by integrating the linear airframe and propulsion system models obtained from separate nonlinear simulations. Details on integrated linear model generation are available in Ref. [12]. The integrated linear design model has the form

$$
\dot{\bar{x}}=A \bar{x}+B \bar{u} ; \bar{y}=C \bar{x}+D \bar{u}
$$

(In the text, the overbar on a variable indicates a vector quantity). The state vector $\bar{x}$ consists of 8 airframe related state variables, which are the three body axes velocities, the three angular rates and the Euler pitch and roll attitudes; and 6 engine related state variables, which are the two rotor speeds and metal temperatures for compressor, bumer and high and low pressure turbines. The control vector $\bar{u}$ consists of 8 airframe related controls, which are the three aerodynamic control effectors - elevator, aileron and rudder; three effective RCS nozzle areas - one each for pitch, roll and yaw control; aft nozzle and ventral nozzle vectoring angles: and 4 engine related controls, which are fuel flow rate, aft nozzle throat area and ventral nozzle exit area and ejector butterfly valve angle which controls the primary flow to the ejectors. The output vector $\bar{y}$ consists of 10 airframe related outputs, which are the airspeed and acceleration along the flight path, the three body axes angular rates, Euler pitch and roll attitudes, flight path angle, and sideslip angle and angular rate, and 4 engine related outputs, which are the fan speed and the gross thrusts from the aft and ventral nozzles and ejectors.

The linear model described above includes "conditioning" in the form of control blending. For instance, only 3 effective RCS areas are used in the linear design model whereas the full nonlinear model has 5 controlled RCS areas. Details of control blending for other control effectors based on open-loop control effectiveness studies and designers' knowledge of system dynamics are discussed in Ref. [12].

The flight phase considered in this study is the decelerating transition during approach to hover landing. During this flight phase, the pilot's main control task is to maintain a steady deceleration along a specified glide path angle. Linear models were initially generated at airspeeds of 60,80 and 100 Knots with flight path at $-3 \mathrm{deg}$. Based on open loop frequency-domain and time-domain analyses of these linear models, it was decided to use the 80 Knots linear model as the nominal design model. The other linear models were used to evaluate the stability and performance robustness of the nominal design, develop controller scheduling and evaluate off-design performance as will be discussed later.

Apart from control blending, further "conditioning" of the linear control design model was performed so that the effects of some of the nonlinearities can be adequately addressed by a "robust" linear control design. This modei "conditioning" consisted of: (a) Normalization of the control inputs and controlled outputs by appropriate maximum values such that the linear control design 
problem formulation is meaningful; (b) Use of ratelimited actuator bandwidths in the linear control design to account for low rate limits on the RCS area actuators; (c) Modifying the design model to treat the RCS commanded bleed flow as a bleed flow disturbance rejection problem within the centralized linear control design framework, thus taking into account the effect of coupling from airframe to the engine through the RCS. Details of this model "conditioning" are discussed in Ref. [8].

\section{Centralized Control Design}

Recent advances in $\mathrm{H}_{x}$ control theory [13] and computational algorithms to solve for $\mathrm{H}_{x}$ optimal control laws [14] have made this theory a viable candidate to be applied to complex multivariable control design problems. In general terms, this technique provides the designer the means to synthesize a controller for "best" guaranteed performance in the presence of "worst case" disturbance (or command). Proper formulation of the control design problem using $\mathrm{H}_{x}$ theory provides for building in stability robustness and obtaining an adequate trade-off between performance and allowable control power in the resulting controller. The results of the preliminary application of $\mathrm{H}_{x}$ control design techniques to IFPC design for the E-7D STOVL aircraft, reported in Refs. $[7,8]$, have been encouraging. So the $\mathrm{H}_{\infty}$ control synthesis technique is being used for the centralized control design portion of IMPAC.

The details of the $\mathrm{H}_{x}$ based centralized control design and evaluation results for the E-7D $80 \mathrm{Knot}$ control design model are available in Refs. [8, 15]. A robust formulation of the $\mathrm{H}_{\infty}$ synthesis technique which uses internal noise models to mimic the effects of model variations [8] was used for the E-7D transition phase centralized control design.

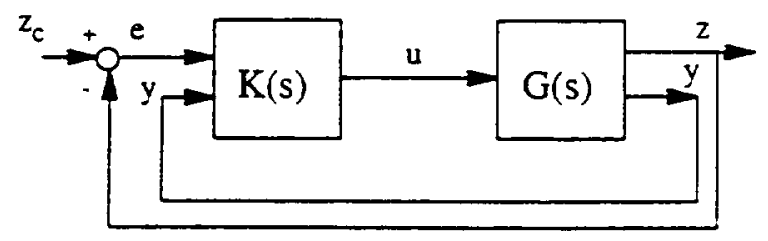

Figure 3 Block Diagram for Centralized Control Design

The centralized controller structure is shown in Fig. $\vec{z}$ with the controlled variables $\bar{z}$ consisting of 5 airframe related variables, which are a velocity variable that is a blend of airspeed and acceleration along flight path, pitch and roll variables that are a blend of Euler attitudes and body axis rates. longitudinal tlight path angle, and sideslip angle; and one engine related variable which is the engine fan speed. The controller inputs are the tracking errors $\bar{e}=\bar{z}_{c}-\bar{z}$, the plant outputs $\bar{y}$ as discussed earlier with the three gross thrust measurements removed and the RCS bleed flow demand added. The choice of the blended variables in $\bar{z}$ corresponds to response types that are desirable for good handling qualities (Refs. [5, 16]) in transition flight. The choice of velocity variable corresponds to designing an acceleration command system with velocity hold, and the choice of pitch and roll variables corresponds to designing a rate command-attitude hold system.

The centralized controller provided decoupled command tracking of the controlled variables $\bar{z}$ up to the desired bandwidth for each individual controlled variable in the presence of the RCS bleed flow nonlinearity, discussed earlier. This type of closedloop system provides independent control of acceleration, pitch, flight path angle, roll and sideslip from the various pilot control effectors such as stick, throttle and rudder pedals etc., thus reducing pilot workload, and also control of the propulsion system operating point (N2) independent of the aircraft motion. Independent control of roll and sideslip will result in a control system that provides automatic tum coordination thus further reducing pilot workload. Shown in Fig. 4 is the response of the $80 \mathrm{Knot}$ centralized closed-loop system to a step flight path command. The rise time for flight path response is within the handling qualities guidelines for Level I response and there is good decoupling in the velocity $(V)$, pitch attirude $(\theta)$ and engine fan speed (N2) response.

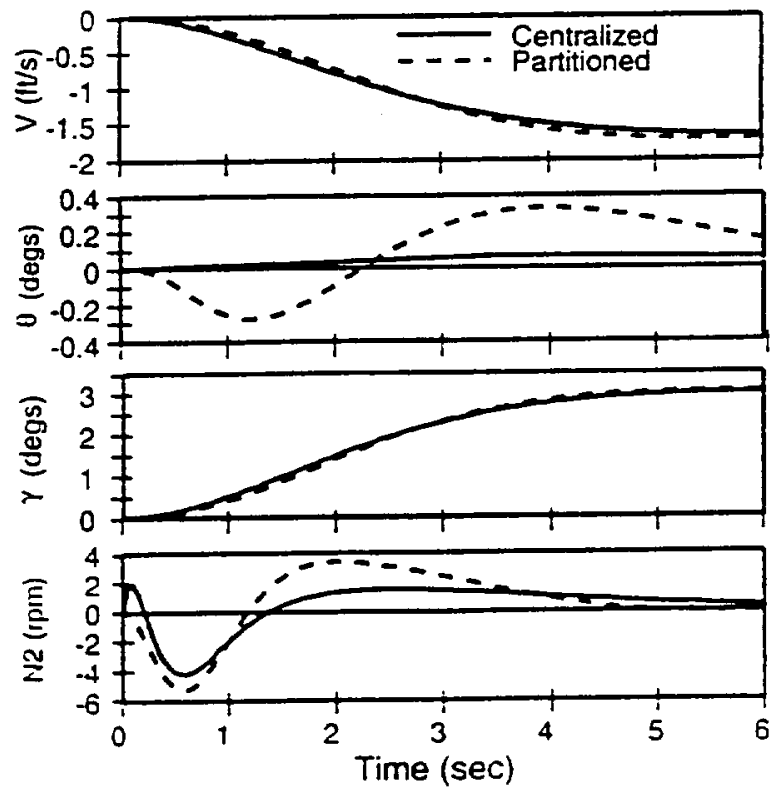

Figure \& 80 Knots Linear Integrated System Response to Step Flight Path Command 


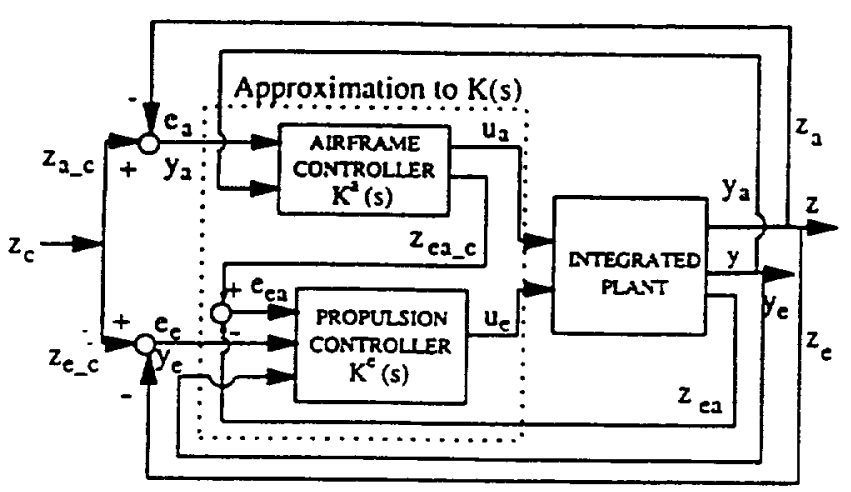

Figure 5 Decentralized. Hierarchical Structure for Controller Partitioning

\section{Controller Partitioning}

As discussed earlier, in an overall aircraft design, traditionally the engine manufacturer needs a separate engine controller to be able to independently perform extensive testing to assure an adequate design and engine integrity. To address this issue and other issues related to implementation of an IFPC design, the centralized controller is partitioned into a decentralized, hierarchical control structure as shown in Fig. 5. In Fig. 5, the subscript "a" refers to airframe quantities, "e" refers to propulsion system quantities, and " $c$ " refers to commands. The intermediate variables, $\bar{z}_{a}$, represent propulsion system quantities that affect the airframe, for example propulsive forces and moments. The controller partitioning problem is essentially that of determining the airframe and engine subcontrollers, $K^{2}(s)$ and $K^{e}(s)$ respectively, that match the closed-loop performance and robustness characteristics with the centralized controller to a desired accuracy. Furthermore the engine subcontroller should provide tracking of the interface variable commands, $\bar{z}_{\text {ea_c }}$ to allow for independent subsystem check-out.

A systematic procedure for obtaining partitioned subcontrollers from a centralized controller is discussed in detail in Ref. [9]. With the centralized controller, $\mathrm{K}(\mathrm{s})$ defined by

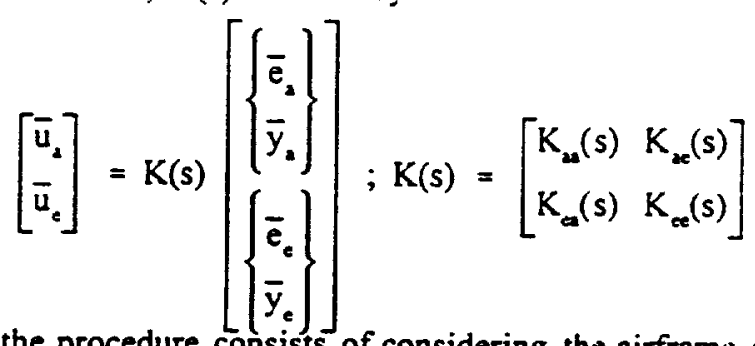

the procedure consists of considering the airframe and engine subcontrollers, $K^{\prime \prime}(s)$ and $K^{e}(s)$ respectively, to have the following structure

$$
\begin{aligned}
& K^{\prime}(s)=\left[\begin{array}{ll}
{[} & K^{l e d}(s)
\end{array}\right] \bar{K}^{1}(s): \\
& K^{e}(s)=\left[\begin{array}{ll}
K_{e s}^{e}(s) & K_{e}^{e}(s)
\end{array}\right]
\end{aligned}
$$

In (3), I is an identity matrix with dimension of airframe controls, $\bar{u}_{1}$, and the other subcontroller matrices are determined using the steps described briefly in the following: (1) A state-space representation of the $K_{e}^{c}(s)$ block of the engine subcontroller is obtained as a reduced order approximation of the $\mathrm{K}_{\mathrm{ex}}(\mathrm{s})$ block of the centralized controller; (2) The response of the interface variables $\bar{z}_{e a}$ to airframe controlled variable commands $\bar{z}_{\mathrm{a}, \mathrm{c}}$ with the centralized controller is analyzed to determine the bandwidth requirements on the engine subsystem for tracking the interface variable commands $\bar{z}_{\text {a }_{-}}$; (3) The $\mathrm{K}_{\mathrm{e}}^{\mathrm{e}}(\mathrm{s})$ portion of the engine subcontroller is designed to meet the tracking bandwidth requirements. determined from step (2), using the errors $\bar{e}_{e s}$ as the feedback variables; (4) With the engine subsystem loop closed using the centralized controller, a statespace representation for $\overline{\mathrm{K}}^{2}(\mathrm{~s})$ is obtained as a reduced order approximation of the system that provides the $\left[\begin{array}{l}\bar{e}_{2} \\ \bar{y}_{2}\end{array}\right] \rightarrow\left[\begin{array}{l}\bar{u}_{2} \\ \bar{z}_{e a}\end{array}\right]$ response with the centralized controller; (5) A lead filter $K^{\text {lead }}(s)$ is designed to compensate for the limited $\bar{z}_{a c}$ tracking bandwidth of the engine subsystem. The application of this controller partitioning procedure to the STOVL example is discussed in Ref. [9]. Internally balanced realization based reduction techniques were used to get the reduced order approximations described in steps (1) and (4) above.

The controller paritioning structure for the STOVL example is shown in Fig. 6 . The blocks marked $\mathrm{K}_{5_{i} i}$ in Fig. 6 correspond to controller
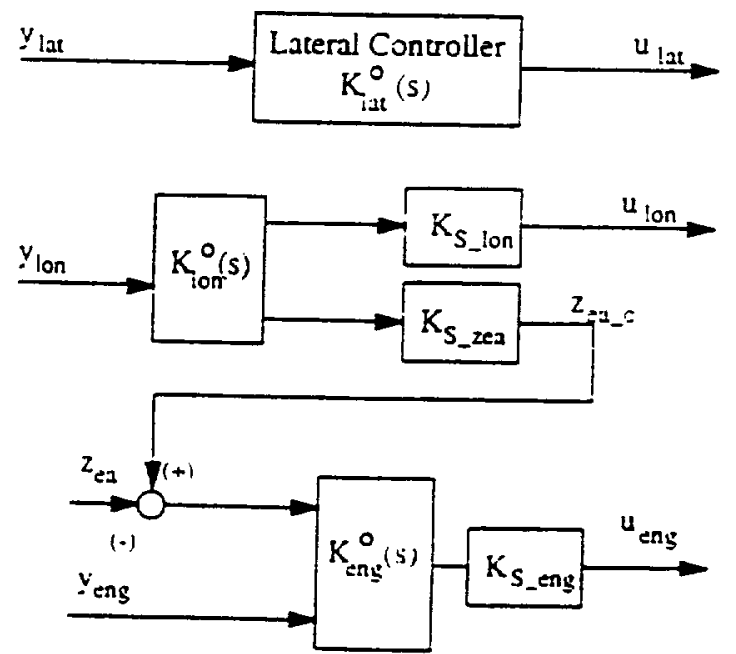

Figure 6 STOVL Controller Partitioning and Controller Scheduling Structure 
scheduling and will be discussed in a later subsection. The partitioning was done in two major steps: first the centralized controller was partitioned into decoupled lateral and longitudinal plus engine subcontrollers and then the longitudinal plus engine subcontroller was further partitioned into separate hierarchical longitudinal and engine subcontrollers using the procedure described above. The inputs $\bar{y}_{\mathrm{lat}}$ to the lateral subcontroller $\mathrm{K}_{\text {lat }}^{\circ}(\mathrm{s})$ consist of errors in tracking the lateral/directional controlled variables (the roll rate and attitude blend and sideslip angle), and lateral/directional portion of the plant outputs $\bar{y}$. The outputs of the lateral subcontroller, $\bar{u}_{\mathrm{lat}}$, consist of the lateral/directional portion of the plant inputs $\bar{u}$, i.e. aileron and rudder deflections, and roll and yaw RCS areas. The inputs and outputs, $\bar{u}_{\text {lon }}, \bar{u}_{\text {eng }}, \bar{y}_{\text {lon }}$, and $\bar{y}_{\text {eng }}$, of the longitudinal and engine subcontrollers, $\mathrm{K}_{\text {ton }}^{\circ}(\mathrm{s})$ and $\mathrm{K}_{\mathrm{eng}}^{\circ}(\mathrm{s})$, respectively, are similarly defined. The interface variables are the gross thrusts from the aft nozzle, the ejectors and the ventral nozzle, FG9, FGE and $F G V$ respectively.

The partitioned subcontrollers closely matched the performance characteristics achieved with the centralized controller and also had similar multivariable gain and phase margins for variations at the plant controlled outputs (Refs. $[9,15])$. The response of the 80 Knots closed-loop system to a step flight path command with the centralized and the partitioned controllers is compared in Fig. 4. The flight path tracking performance and the decoupling in the velocity and engine fan speed response is maintained by the partitioned subcontrollers. Although there is increased coupling in the pitch response with the partitioned subcontrollers, the pitch disturbance from the trim value of $7 \mathrm{deg}$ is still quite small considering the large flight path command. It was decided to proceed with these subcontrollers to the next step in the IMPAC design procedure, while continuing to investigate in a parallel study the possibility of improving upon these subcontrollers using the state-space parameter optimization based procedure described in Ref. [17].

\section{Full Envelope Subsystem Control Design}

This step in IMPAC methodology consists of two major substeps which are controller scheduling and trim control generation. The STOVL application of these two steps is discussed in the following.

\section{Controller Scheduling}

The general approach to controller scheduling is to design linear controllers at various operating points and then perform some kind of curve fit to the various controller gains with the critical operating point conditions as the independent parameters. With multivariable paritioned subcontrollers obtained above, the number of parameters to be scheduled may be quite large. A simpler controller scheduling scheme that exploits the robustness properties of the nominal controller was used for this design study.

The structure for scheduling of the partitioned subcontrollers is as shown in Fig. 6 where the blocks marked $\mathrm{K}_{\mathrm{s}_{i}}$, with " $\mathrm{i}$ " representing "lon", "zea" and "eng", are gain matrices which are functions of the aircraft speed (V). The controller is scheduled with the airspeed because the airrame dynamics and also the aircraft trim configuration change significantly with the change in airspeed over the transition flight envelope. The controller was not scheduled with the flight path angle because it was decided early on to limit the piloted evaluation of the IMPAC based IFPC design to the decelerating landing approach around a $-3 \mathrm{deg}$ glide slope. The controller scheduling matrices are identity for the nominal design model and were obtained for two off-design linear models, corresponding to airspeeds of 60 and 100 Knots with flight path angle held at $-3 \mathrm{deg}$, by using the procedure described below. Note that, as shown in Fig. 6, the lateral controller is not scheduled with speed because satisfactory performance was obtained at the off-design points with the nominal lateral subcontroller.

The steps in developing the schedules for offdesign linear models are: (a) Synthesizing the longitudinal control schedule $\mathrm{K}_{\mathrm{s}_{-} \text {lon }}$ and an intermediate engine control schedule $\left(\tilde{K}_{S_{-} \text {eng }}\right)$ to match the nominal centralized controller performance and robusmess at the off-nominal design points; (b) Synthesizing the interface variables schedule $\left(\mathrm{K}_{\mathrm{s}_{-} \text {zea }}\right)$ such that the offnominal longitudinal controller $\bar{z}_{\mathrm{ea}}$ output response to the inputs $\bar{y}_{\text {lon }}$ closely matches the $\bar{y}_{\text {lon }} \rightarrow \bar{z}_{e a}$ response of the off-nominal system with the engine subsystem loop closed using the intermediate schedule $\tilde{\mathrm{K}}_{\mathrm{s}_{\text {_eng }}} ;$ (c) Synthesizing the engine schedule $K_{s}$ such that the off-nominal engine subsystem closed-loop response closely matches the nominal response.

With the controller scheduling discussed above, there are only 41 parameters to be scheduled 16 each for $K_{s_{3} \text { lon }}$ and $K_{s_{\text {_eng }}}$ and 9 for $K_{s_{-} z \text {. The }}$ details of this controller gain scheduling procedure and its application to the STOVL example will be documented in a future publication. Briefly, the controller scheduling gains in each of the steps outlined above were determined using a constrained parameter optimization approach with an appropriate formulation of the cost function to be minimized. The 


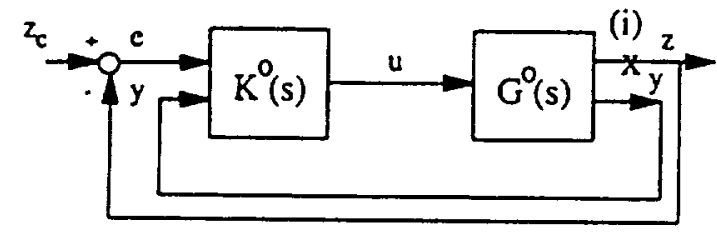

(a) Nominal Control Loop

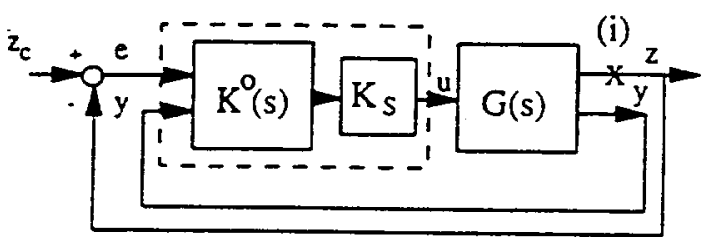

(b) Off-Design Control Loop

Figure 7 Generic Formulation for Synthesizing Controller Scheduling Gains

generic optimization approach, as shown in Fig. 7, consisted of determining $\mathrm{K}_{\mathrm{s}}$ such that the loop transfer function matrix with the loops broken at the controlled outputs (point (i) in Fig. 7) for the off-nominal plant dynamics "closely" matches the nominal loop transfer function response. This idea can be mathematically stated as:

$$
\min _{K_{S}}\left\|E_{2 l p}(j \omega)\right\|_{\text {。 }}
$$

where $E_{z p}(s)$ is the difference between the nominal and the off-nominal loop transfer response at the controlled outputs. The optimization was done using the Optimization Module of the MATRLX $_{x}$ family of products [18] which is fully integrated with a graphical block diagram manipulation software and allows for calculating cost functions of the form (4) directly from block diagram representations of the type shown in Fig. 7. The elements of $K_{s}$ were bounded by upper and lower limits to avoid excessive control usage and the eigenvalues of the off-nominal closed-loop system were constrained to be in the left-half plane to guarantee closed-loop stability with the scheduled controllers.

Shown in Fig. 8 is the response of the linear closed-loop system, with partitioned and scheduled controllers, to a step flight path command for airspeeds $\mathrm{V}=60,80$ and 100 Knots. The controller scheduling maintains the nominal ( $80 \mathrm{Knot}$ ) flight path tracking and velocity decoupling response. Similar comparisons for other commands indicated that in general the off-design model scheduled system closedloop response showed very little degradation from the response for the nominal design point closed-loop system. The scheduling scheme was later extended to the 120 Knots, $\gamma=0$ flight condition to provide adequate airspeed envelope for pilots to evaluate the IFPC design during the decelerating transition phase.
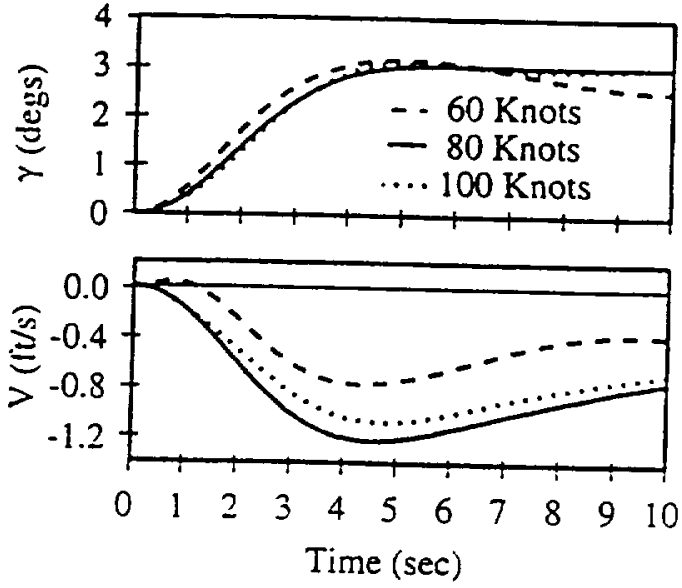

Figure 8 Linear System Response with Controller Scheduling

Although the controller scheduling did not provide a good match with the nominal performance for this operating point, because the airframe and engine dynamics at 120 Knots are significantly different from those at 80 Knots, it was decided to proceed with the next step in the IMPAC methodology with this simplified controller scheduling scheme. The smoothing of the longitudinal and engine control schedules was done by linearly interpolating between the $\mathrm{K}_{\mathrm{s}_{-} \text {lon }}, \mathrm{K}_{\mathrm{s}_{-} \text {zea }}$ and $\mathrm{K}_{\mathrm{s}_{\text {eng }}}$ schedules for the 60,80 , 100 and 120 Knots designs.

\section{Trim Control Generation}

The trim command generator consists of three major elements: the pilot gradients; the flight configuration management generator (CMG); and the engine CMG. The pilot gradients are derived from handling qualities specifications and convert the pilot inputs $\left(\bar{\delta}_{p}\right)$, such as latera//longitudinal stick deflections etc., into physical variable commands $\left(\bar{z}_{p_{S} \text { SEI }}\right)$, such as pitch and roll rate, to the control system. Based on the pilot selected velocity and flight path commands ( $V_{S E}$ and $\left.\gamma_{S E L}\right)$. the flight $C M G$ generates steady-state trim commands for the airframe longitudinal controls (elevator Se, ventral nozzle vectoring angle ANG79, and aft nozzle vectoring angle ANG8) and the gross thrusts from the aft and ventral nozzles and ejectors, FG9, FGV and FGE respectively. The flight $\mathrm{CMG}$ is designed based on the trim maps obtained from the airframe six dof simulation with a simplified installed performance model of the engine. The trim strategy used is to hold the aircraft pitch attitude and longitudinal controls ( $\delta e$, ANG79 and ANG9) constant and trim the aircraft using the different levels of the three gross thrusts FG9, FGV and FGE. The engine CMG generates the trim commands for the engine controls (fuel flow rate 
WF, aft nozzle area $A 8$, ejector butterfly valve angle ETA, and ventral nozzle area A78) which meet the trim thrust requirements, as generated by the flight CMG, while keeping the engine on a desired fan speed (N2) operating schedule.

\section{Subsystem Nonlinear Control Design}

For the airframe control, the full envelope design accounts for most nonlinear dynamics. Operational safety might require some additional limiting such as Angle of Attack ( $\alpha$ ) limiting. For the STOVL IFPC design, the pilot commanded pitch attitude was limited such that for a given flight path command the resulting angle of attack command stays within the operational limits of 4 to $14 \mathrm{deg}$. Rate command limiting was added to the pilot commanded flight path and acceleration to avoid saturation of actuators due to excessive commands. RCS distribution and limit logic was added which distributes the three effective RCS area commands to the five RCS nozzle area actuators (as discussed in Ref. [8]) and also limits the total RCS bleed flow demand to the maximum allowable value.

For the propulsion system, a fan speed schedule was added which determines a commanded value for the engine fan speed (N2J) based on the total gross thrust commands from the airframe controller, such that the engine operates in an efficient manner within desired stability margins. Engine safety limits are often encountered during normal transients. Extensive limit logic has to be added to the propulsion control system for operational safety. A discussion of the typical operational limits for a turbofan engine is provided in Ref. [11]. The engine safety limits implemented in the STOVL example are the fuel flow accel and decel schedule, the fan rotor over-speed, the minimum burner pressure, and the fan surge margin limit. The accel schedule accounts for the fan turbine inlet temperature limit, basically limiting the rate of change of the fuel flow so that the fuel/air mixture ratio is within an acceptable range. Once the actuator commands are bounded as required, the resulting commands are sent to the actuators.

Although the IFPC design was developed to keep control requirements within reasonable limits, it is normal to encounter actuator saturation limits within the aircraft flight envelope. Also, incorporating the propulsion system operational limits discussed above requires limiting the outputs of the controller. For multivariable control with dynamic states, as those developed for the STOVL IFPC design, it is important to provide integrator wind-up protection to properly accommodate the effects of actuator limits. Shown in Fig. 9 is a block diagram for implementing the general antiwindup and bumpless transfer (AWBT) scheme

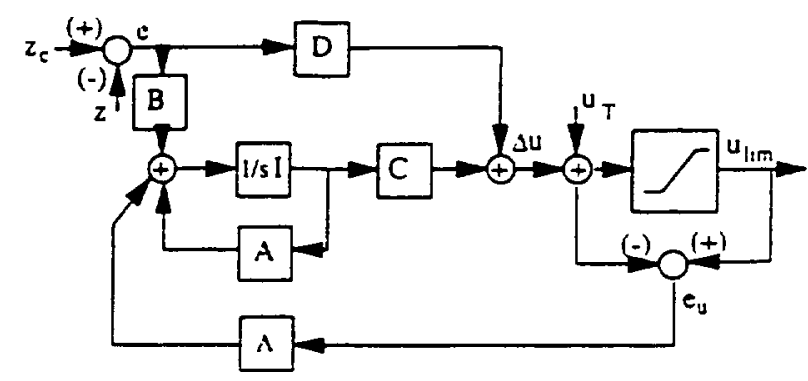

Figure 9 Generic Block Diagram for Implementing Integrator Wind-up Protection

discussed in detail in Refs. $[19,20]$. In Fig. 9, the matrices $A, B, C$ and $D$ correspond to the state-space system matrices of the controller (for instance the partitioned airframe or engine linear controller for the STOVL example), $\Delta \mathrm{u}$ is the small perturbation control command output of the linear controller, $u_{t}$ is the trim control command from the configuration generator, $u_{i \mathrm{im}}$ is the limited value of the control command where the limiting block might represent actuator hardware limit or some limit imposed due to the operational safery implementation logic, and $\Lambda$ is the matrix of integrator wind-up protection gains. As seen from Fig. 9, the integrator wind-up protection loop becomes active only when the control command exceeds the specified limit, causing $e_{u} \neq 0$. Then the product of $e_{u}$ and the gains $\Lambda$ modify the controller such that the control command for the limited actuator tracks the limit value.

For the STOVL IFPC design. the integrator wind-up protection (IWP) gains $\Lambda$ were initially determined using the approach suggested in Refs. [19, 20]. However, it was discovered that the approach of Refs. $[19,20]$ guarantees only the stability of the modified controller and can result in severe degradation in the closed-loop system performance when the actuator limits are encountered. In some instances, this scheme even resulted in the closed-loop system being unstable with the modified controller. A parameter optimization scheme was then developed

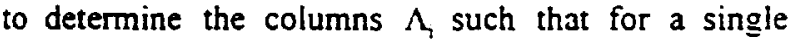
actuator saturation the modified controller and the closed-loop system will remain stable while minimizing the loss in tracking performance compared to the "unlimited" system performance. The details of this optimization procedure will be documented in a future publication. The gains $\Lambda_{1}$ were synthesized using this approach to accommodate limits on the outputs of the lateral controller (aileron, rudder, roll and yaw RCS commands), the longitudinal controller (elevator, pitch RCS, ventral and main nozzle vectoring angles and the ejector, ventral and main 


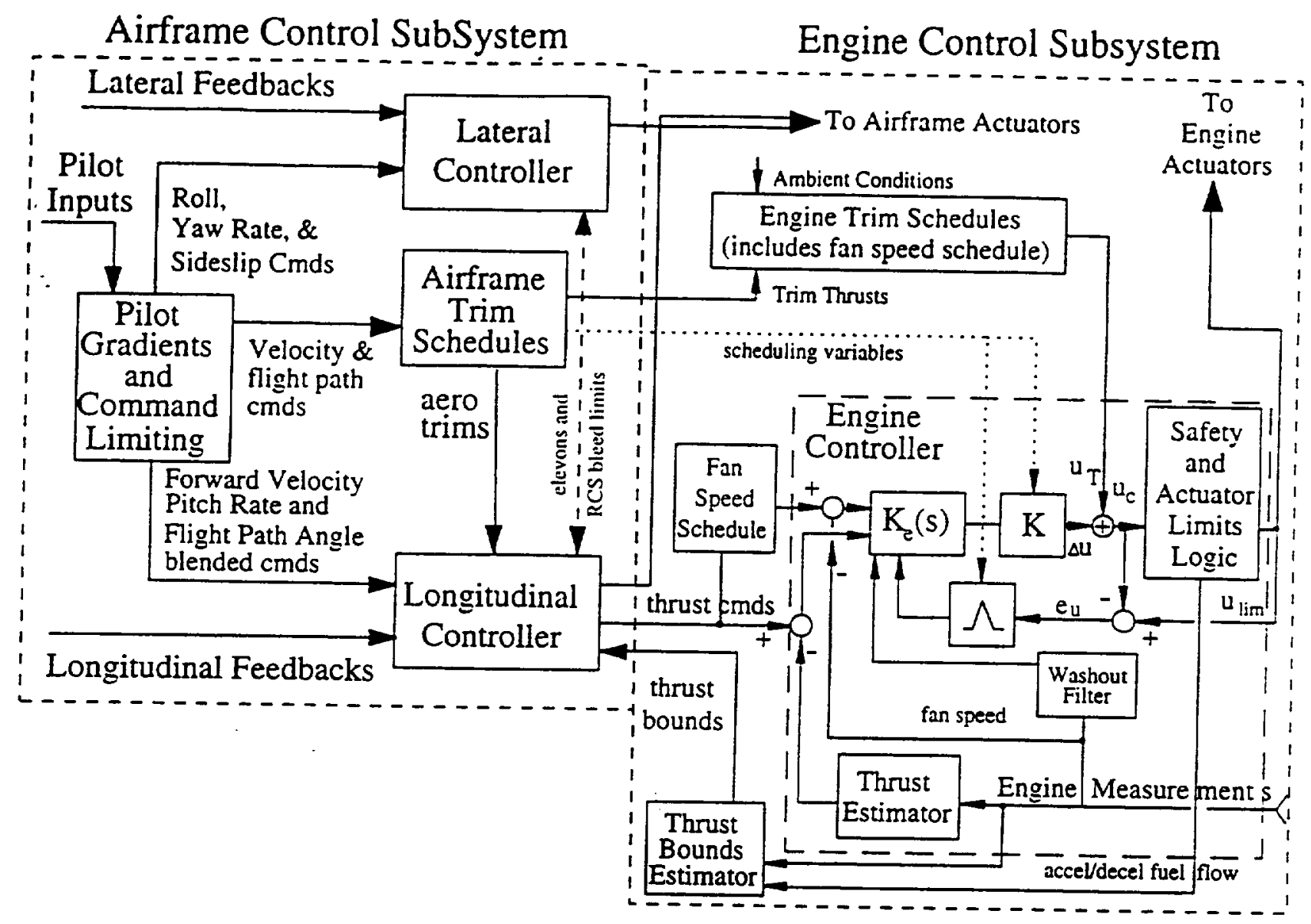

Figure 10 Partitioned, Integrated Controller with Details of Engine Controller

nozzle thrust commands), and the engine controller (main burner fuel flow, aft nozzle and ventral nozzle areas and ejector butterfly angle commands). The gains $\Lambda_{i}$ for the longitudinal and engine controllers were determined for the 4 linear models at the 60,80 , 100 and 120 Knots and were interpolated linearly as a function of velocity. Since the E-7D aircraft is equipped with left and right elevons, a roll command priority logic was implemented in converting the elevon limits to elevator and aileron limits.

\section{Full System Controller Assembly and Evaluation}

The full system controller was assembled in stages. After a new block was integrated into the simulation, closed-loop time histories were compared to the time histories of the previous stage. For example, the airframe trim schedules resulting from step 4 (Full Envelope Subsystem Control Design) were added to the partitioned control system that had resulted from step 3 (Controller Partitioning). After working out the initial conditions, time responses to typical pilot commands were compared to the previous closed-loop system containing the partitioned controller that did not include the trim schedules. This allowed the time constants for the low pass filters used with the scheduling variables to be selected so that the closed-loop response of the system with "total" (trim plus perturied) actuator commands and "total" measurements would match the "perturbation only" closed-loop responses. Similarly, limit logic was added after the closed-loop system had been converted to "total" variables and then the effects of actuator and safety limits could be ascertained for large commands, (this will be discussed in more detail in the following). This allowed the effects of integrator windup and limit protection gains to be analyzed. Once the full system, continuous controller had been evaluated, a discrete version of this controller was generated and new closed-loop time histories were generated and compared to time histories of the continuous controller. In this manner, the closed-loop, assembled system was constructed in stages.

Fig. 10 shows the assembled, hierarchical control system with the partitioned airframe and engine subcontrollers. The airframe control subsystem consists of four main sections: the pilot gradients and command limiting block; the lateral controller; the longitudinal controller; and the airframe trim schedules. The pilot gradient and command limiting block provides rate and range limits, command 
coupling, and scales the pilot inputs to appropriately sized commands. This block is generated as a result of the nonlinear design in step 5 . The resulting commands are then passed to the lateral and longitudinal dynamic controllers. The velocity and flight path commands are passed to the airframe trim schedules. The lateral and longitudinal dynamic controller blocks consist of a state space dynamic controller, (from step 3); a gain scheduling matrix, (from step 4); and scheduled integrator windup and limit protection gains, (from step 5). The components of the lateral and longitudinal controllers are similar to those for the engine controller which are shown in detail in Fig. 10 and will be discussed later in this section. The lateral control system maintains closedloop control of roll rate, yaw rate and the sideslip angle using the ailerons, rudder, and roll and yaw RCS. The longitudinal control system maintains closed-loop control of pitch angle and rate, forward velocity and acceleration, and the flight path angle using the elevons, aft nozzle angle, ventral nozzle angle, pitch RCS, and thrust from the aft and ventral nozzles and the ejectors. The trim schedules, generated during step 4, provide the nominal steady state operating point information for all of the actuators, including the trim thrusts, which are passed to the engine suhe three thrust commands.

For the lateral, longitudinal and engine controllers, the total actuator command values are checked for actuator range limits and bounds in the limit logic block. Limits are imposed on the command values if any of the safety limits are violated. The actuation error, $e_{u}=u_{l i m}-u_{c}$, is fed back to the dynamic controller for use in the integrator windup and limit accommodation scheme, as shown in Fig. 10 and as previously described in Fig. 9. While normally the IWP gains for the propulsion system would be schedule with an engine variable, for this STOVL problem the IWP gains were scheduled as a function of aircraft velocity to facilitate rapid implementation.

Consistent with the $H_{x}$ formulation of the engine control law, (Ref. [12]), the engine fan speed is fed back to the dynamic engine controller as shown in Fig. 10. A washout filter was provided on this fan speed feedback to remove the steady state effects of this feedback. Thrust bounds are fed back from the engine subcontroller to the longitudinal airfame controller. These thrust bounds implement rate and range limits and the bounds are updated at every time step. Calculating the thrust bounds is nontrivial. because when the core engine mass flow is limited, (i.e. maximum total engine thrust or a rate limited total thrust), the resulting thrust error can be distributed over the three thrust ports in any manner. Based on the philosophy that the thrust is not truly limited until the engine is on a fuel flow limit, the thrust estimator was used to calculate the thrust bounds by estimating the engine thrust at the current engine conditions with the fuel flow command replaced by the accel and decel fuel flow limit values. Feeding the decel fuel flow into the thrust estimator provides a minimum thrust bound for all nozzles and using the accel fuel flow provides a maximum thrust bound. In retrospect it would appear that assigning a higher priority to the ejector and ventral nozzle thrust, at the expense of the aft nozzle thrust, could have reduced some of the pitch oscillations that were experienced during engine actuator limits, as will be discussed shortly.

A comparison of the small and large transient time history responses of the nonlinear, nonreal-time. closed-loop simulation are shown in Fig. 11 and 12. This comparison is useful because it shows the difference between the small transient response and large transient response that encounters the system nonlinearities including actuator limits. Fig. 11 shows the small transient response for a deceieration of $-0.193 \mathrm{f} / \mathrm{s}^{2}$, and a change in flight path angle of -0.3 degs. Fig. 12 shows the large transient response for a deceleration of $-1.93 \mathrm{f} / \mathrm{s}^{2}$ and a change in flight path angle of -3 degs, which is an order of magnituce larger than the small transient command. Note that the $y$-axis scales are different for Figs. 11 and 12. Also note that the initial trim point for this simulation was not perfect and there is an intitial settling transient between 0 and 10 seconds in some of the time traces.

The small transient responses in Fig. 11 show good velocity rate tracking and velocity hold. and good tracking of the commanded flight path angle. There is a small but acceptable coupling in the velocity rate response due to a flight path command. Also note the built-in command coupling between flight path command and pitch angle command in $\mathrm{Fig}$ 11 (c). This command coupling is used to reduce the effects of out-of-phase coupling between the flight path command and the pitch response from 120 Knots (202.5 fps) to 100 Knots (169 fps). This command coupling is phased-out from 100 Knots to 80 Knots (135 fps). Note that in the small transient response. no limits are encountered. Fig. 11(f) shows the pitch RCS arez AQR, and the ventral nozzle angle, ANG79, responses for later comparison to the large transient response in Fig. 12.

One problem that did occur can be seen in Fig. $11(e)$. The elevator, $\delta e$, and the aft nozzle angie. ANG8, are effectively fighting each other. This cancellation does not occur at the 80 Knots linear design point. The conflict is caused by the gain scheduling matrices used to redistribute the control 

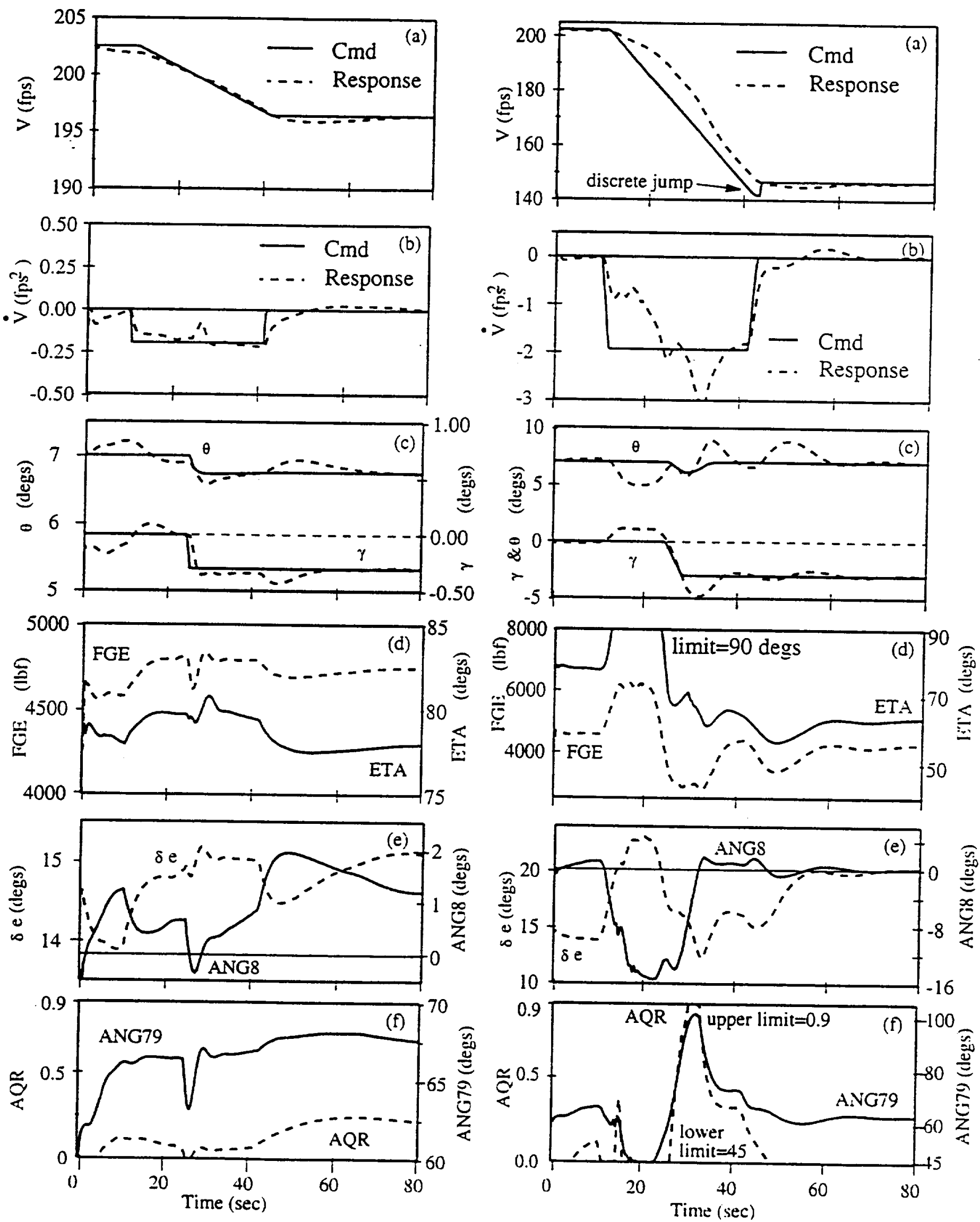

Figure 11 Small Transient Command Response 
effectiveness at the 60,100 , and 120 Knots off-design points. With actuator redundancies there are infinite solutions to the optimization problem used to determine the controller scheduling gains. Although, the gain scheduling does a good job of matching the off-design point performance with that for the 80 Knots design point, as was shown in Fig. 8, the scheduling gains are such that two actuators are cancelling each other. In retrospect, additional constraints could have been imposed in the optimization problem to force a unique solution that would avoid actuator conflicts, or additional actuator blending could have been performed prior to controller gain scheduling optimization. The actuator conflict does not detract from the small transient response shown in Fig. 11, however, the conflicting actuators could have contributed more meaningfully towards improving the large transient response as will be discussed next.

For the large transient response shown in Fig. 12 , the velocity command is tracked well during the deceleration from 120 Knots (202.5 fps) to about 93 Knots (157 fps). However, there is a noticeable deviation in pitch and flight path angle. This deviation is caused by the engine encountering an ejector butterfly valve angle limit of 90 degrees as shown in Fig. 12(d). This engine actuator limit reduces the amount of ejector thrust available, thereby unbalancing the pitching moment. At the 80 Knots design point more than $60 \%$ of the weight of the aircraft is supported by propulsive, rather than aerodynamic lift. This propulsive lift is provided mainly by the ejectors and the ventral nozzle. The thrust between the ventral nozzles and ejectors, along with the moment provide by the elevator, must be appropriately balanced in order to maintain the desired pitching moment. This is an example of the controller directionality problem during actuator limits as discussed in Refs. $[19,20]$. The engine integrator windup protection attempts to maintain the thrust performance during the ejector limit. The airframe integrator windup protection engages when the pitch RCS saturates at a value of 0.9 , in an attempt to balance the pitching moment after the ejector butterfly valve saturates, as shown in Fig. 12(f). Fig 12(f) also shows that the ventral nozzle swings fully backward and saturates at 45 degrees in an attempt to reduce the downward pitching moment caused by the ventral nozzle. The system does maintain closed-loop stability, but a better, less oscillatory, pitch response is desired. As discussed above, if the elevator and att nozzle angle were not conflicting, perhaps their control authority could have been used to reduce this pitch oscillation. Figure 12(e) shows that these two actuators generally oppose each other. Also, as mentioned during the discussion of the calculation of the thrust bounds, if more emphasis was given to maintaining the ejector and ventral nozzle thrusts, or perhaps a ratio of these thrusts, then the pitch oscillations could be reduced at the expense of a slower, rate limited, flight path or velocity response.

Fig. 12(a) contains a jump in the velocity command trace that needs to be explained. The integrated system was designed for transient acceleration command tracking and steady-state velocity hold. In transition flight, long decelerations are typical and a velocity tracking error would build up. This constant offset would cause the ventral nozzle angle to swing forward to the limit. Rather than redesigning the integrated system for a deceleration hold mode, a washout filter was placed on the velocity error signal to reduce the effects of this error as long as a nonzero velocity rate command was given by the pilot. This prevents the integral of the velocity error from driving the ventral nozzle to the limit during long deceleration commands. However, during preliminary fixed-based evaluations, the pilots complained that the controller would not hold velocity after zeroing the velocity rate command. This was because zeroing out the velocity rate command removed the velocity error washout. The velocity hold integral would then drive the velocity to the commanded value which would be different from the actual aircraft velocity. To resolve this problem, additional logic was added to reset the commanded velocity to the actual velocity when the pilot zeroes the velocity rate command. Thus. there is a discrete jump in the commanded velocity when the velocity rate command returns to zero, as shown in Fig. 12(a) and $12(\mathrm{~b})$.

The IMPAC methodology allowed the closedloop, nonlinear system to be analyzed and it enabled the above described limit problem to be isolated to the limit protection scheme and to the way acruator redundancies were handled in the integrated control design. While a better nonlinear response was desired. it was decided to continue on to a fixed-base, piloted evaluation of this control system in order to exercise all of the steps in the IMPAC methodology. With the limited time that was available, the focus was to completely exercise the IMPAC methodology on an example design rather than to get the "optimal" IFPC design for the E-7D aircraft.

Fixed-base piloted evaluation of this IMPAC based IFPC design was conducted at the NASA Lewis piloted simulation facility and the evaluation results are reported in Ref. [21]. Briefly, the pilots were successfully able to complete typical transition phase control tasks such as a constant deceleration with tight control of the flight path for a curved landing 
approach, and landing abort and go around sequence which requires maintaining constant acceleration while climbing and banking to turn. Except for large pitch deviations due to large decel commands, which were caused by multiple actuator saturations as discussed earlier, the pilots found the aircraft response to be predictable and commented favorably on the decoupling between the flight path and velocity response. These successful results with the "first iteration" IMPAC based IFPC design demonstrate the strength of the IMPAC methodology in meeting the integrated control needs for advanced aircraft configurations with significant airframe/engine interactions.

\section{Conclusions}

Steps in IMPAC (Integrated Methodology for Propulsion and Airframe Control), an advanced methodology for Integrated Flight/Propulsion Control (IFPC) design, were discussed with emphasis on application to IFPC design for an ejector-augmentor Short Take-Off and Vertical Landing (STOVL) aircraft in transition phase flight. Various technologies that are relevant to practical use of multivariable control design techniques were developed as part of this design study. These technologies are: (a) A generic command tracking problem framework for robust control law synthesis using H-Infinity control design techniques with rules of thumb for selecting various frequency weights in the design procedure; (b) A systematic procedure for partitioning a centralized controller into a decentralized, hierarchical subsystem controllers; (c) A simplified scheme for controller scheduling which exploits the robustness properties of centralized/partitioned control designs; and (d) A modified scheme for designing integrator wind-up protection gains which guarantees closed-loop system stability for single actuator saturation. Results from a full nonlinear, nonreal-time evaluation of the IMPAC based design indicate that the IFPC system provides the desired command tracking response for acceleration and flight path tracking commands which are the typical pilot tasks for transition flight phase. The IFPC system response could be further improved by proper accommodation of multiple actuator saturation limits that were encountered during large transient commands.

\section{References}

[1] Smith, K.L., "Design Methods for Integrated Control Systems," AFWAL-TR-86-2103, Wright Patterson AFB, OH, December 1986.

[2] Shaw, P.D., Rock, S.M., and Fisk, W.S., "Design Methods for Integrated Control Systems,"AFWAL-
TR-88-2061, Wright Patterson AFB, OH, June 1988. [3] Garg, S., Mattern, D.L., and Bullard, R.E., "Integrated Flight/Propulsion Control System Design Based on a Centralized Approach," Journal of Guidance, Control and Dynamics, Vol. 14, No. 1, Jan.-Feb. 199I, pp. 107-116.

[4] Mattem, D.L., Garg, S., and Bullard, R.E., "Integrated Flight/Propulsion Control System Design Based on a Decentralized, Hierarchical Approach," AIAA Paper 89-3519, presented at the AIAA Guidance, Navigation and Control Conference, Boston, MA, August 1989.

[5] Adibhatla, S., et al., "STOVL Controls Technology," final repor for NASA contract No. NAS3-25193, General Electric Aircraft Engines, Evendale, OH, March 1994.

[6] Weiss, C. et al., ."STOVL Controls Integration Program," final report for NASA contract No. NAS325194, Pratt \& Whimey, West Palm Beach, FL, October 1993.

[7] Garg, S., Ouzts, P., Lorenzo, C.F., and Mattern, D.L., "IMPAC - an Integrated Methodology for Propulsion and Airfiame Control," 1991 American Control Conference, Boston, MA, June 1991.

[8] Garg, S., "Robust Integrated Flight/Propulsion Control Design for a STOVL Aircraft Using H-Infinity Control Design Techniques," Automatica, Vol. 29, No. 1, pp. 129-145, 1993.

[9] Garg, S., "Partitioning of Centralized Integrated Flight/Propulsion Control Design for Decentralized Implementation," IEEE Trans. on Control Systems Technologv, Vol. 1, No. 2, pp. 93-100, 1993.

[10] Akhter, M.M., Vincent, J.H., Berg, D.F., and Bodden, D.S., "Simulation Development for US/Canada Control Technology Program," Proceedings of the Twentieth Annual Modeling and Simulation Conference. University of Pittsburgh, Pittsburgh, PA, June 1989.

[11] Mattern, D.L., and Garg, S., "Propulsion System Performance Resulting from an Integrated Flight/Propulsion Control Design," 1992 AIAA Guidance, Navigation and Control Conference, Hilton Head, SC, August 1992.

[12] Garg, S., Martern, D.L., Bright, M.M., and Ouzts, P.J., "H-Infinity Based Integrated Flight/Propulsion Control Design for a STOVL Aircraft in Transition Flight," AIAA Paper 90-3335, Guidance, Navigation and Control Conference, Portland, OR, August 1990.

[13] Doyle. J.C.. Glover, K., Khargonekar. P.P., and Francis, B.A., "State-Space Solutions to Standard H2 and Ho Control Problems," IEEE Transactions on Automatic Control, Vo. 34, No. 8, Aug. 1989, pp. $831-8+7$ 
[14] "MATRIXx Robust Control Module - User's Guide," Integrated Systems Inc., Santa Clara, CA, October 1989.

[15] Garg, S., and Mattern, D.L., "Application of an Integrated Flight/Propulsion Control Design Methodology to a STOVL Aircraft," AIAA Paper 91-2792, Guidance, Navigation and Control Conference, New Orleans, LA, August 1991.

[16] "Military Specification - Flying Qualities of Piloted V/STOL Aircraft," MIL-F-83300, Wright Patterson AFB, OH, December 1970.

[17] Schmidt, P., Garg, S., and Holowecky, B., "A Parameter Optimization Approach to Controller Partitioning for Integrated Flight/Propulsion Control Application," IEEE Transactions on Control Systems Technology, Vol. 1, No. 1, pp. 21-36, 1993.

[18] "MATRIX ${ }_{x}$ Optimization Module," Integrated Systems Inc., Santa Clara, CA, October, 1989.

[19] Campo, P.J., Morari, M. and Nett, C.N., "Multivariable Anti-Windup and Bumpless Transfer: A General Theory," 1989 American Control Conference, Pittsburgh, PA, June 1989, pp. 1706-1711. [20] Mattern D., "A Comparison of Two MultiVariable Integrator Windup Protection Schemes", ALAA-93-3812, Guidance, Navigation, and Control Conference, Monterey, CA, August 1993.

[21] Bright, M.M., Simon, D., Garg, S., and Mattern, D., "Piloted Evaluation of an Integrated Methodology for Propulsion and Airframe Control Design," AIAA Paper No. 94-3612, Guidance, Navigation and Control Conference, Scottsdale, AZ, August 1994. 


\begin{tabular}{|c|c|c|c|c|}
\hline \multicolumn{3}{|c|}{ REPORT DOCUMENTATION PAGE } & & $\begin{array}{l}\text { Form Approved } \\
\text { OMB No. 0704-0188 }\end{array}$ \\
\hline \multicolumn{5}{|c|}{ 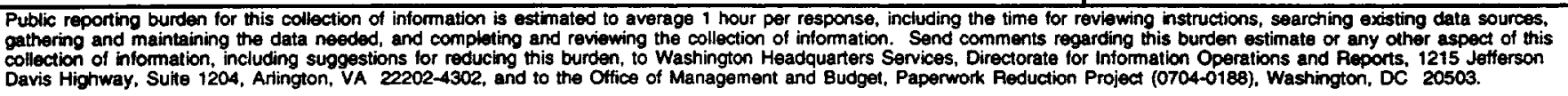 } \\
\hline 1. AGENCY USE ONLY (Leave blank) & $\begin{array}{l}\text { 2. REPORT DATE } \\
\text { September } 1994\end{array}$ & \multicolumn{3}{|c|}{$\begin{array}{l}\text { 3. REPOAT TYPE AND DATES COVERED } \\
\text { Technical Memorandum }\end{array}$} \\
\hline \multicolumn{3}{|c|}{$\begin{array}{l}\text { 4. TITLE AND SUBTITLE } \\
\text { Application of an Integrated Methodology for Propulsion and Airframe Control } \\
\text { Design to a STOVL Aircraft }\end{array}$} & \multicolumn{2}{|c|}{ 5. FUNDING NUMBERS } \\
\hline \multicolumn{3}{|c|}{ 6. AUTHOR(S) } & \multicolumn{2}{|c|}{ WU-505-62-50 } \\
\hline \multicolumn{3}{|c|}{$\begin{array}{l}\text { 7. PERFORMING ORGANIZATION NAME(S) AND ADDRESS(ES) } \\
\text { National Aeronautics and Space Administration } \\
\text { Lewis Research Center } \\
\text { Cleveland, Ohio } 44135-3191\end{array}$} & $\begin{array}{l}\text { 8. PERF } \\
\text { REPC }\end{array}$ & $\begin{array}{l}\text { OAMING OAGANIZATION } \\
\text { ORT NUMBER } \\
104\end{array}$ \\
\hline \multicolumn{3}{|c|}{$\begin{array}{l}\text { National Aeronautics and Space Administration } \\
\text { Washington, D.C. } 20546-0001\end{array}$} & \multicolumn{2}{|c|}{$\begin{array}{l}\text { NASA TM-106729 } \\
\text { AIAA-94-3611 }\end{array}$} \\
\hline \multicolumn{5}{|c|}{$\begin{array}{l}\text { 11. SUPPLEMENTARY NOTES } \\
\text { Prepared for the Guidance, Navigation and Control Conference sponsored by the American Institute of Aeronautics and Astronautics, Scottsdale, } \\
\text { Arizona, August 1-3, 1994. Sanjay Garg, NASA Lewis Research Center; Duane Mattern, NYMA, Inc., 2001 Aerospace Parkway, Brook Park, Ohio } \\
44142 \text { (work funded by NASA Contract NAS3-27186). Responsible person, Sanjay Garg, organization code 2550, (216) 433-2355. }\end{array}$} \\
\hline \multicolumn{3}{|c|}{$\begin{array}{l}\text { Unclassified - Unlimited } \\
\text { Subject Categories } 07,08 \text { and } 63\end{array}$} & \multicolumn{2}{|c|}{ 12b. DISTRIBUTION CODE } \\
\hline \multicolumn{5}{|c|}{$\begin{array}{l}\text { An advanced methodology for Integrated Flight Propulsion Control (IFPC) design for future aircraft, which will use } \\
\text { propulsion system generated forces and moments for enhanced maneuver capabilities, is briefly described. This method- } \\
\text { ology has the potential to address in a systematic manner the coupling between the airframe and the propulsion sub- } \\
\text { systems typical of such enhanced maneuverability aircraft. Application of the methodology to a Short Take-Off Vertical } \\
\text { Landing (STOVL) aircraft in the landing approach to hover transition flight phase is presented with brief description of } \\
\text { the various steps in the IFPC design methodology. The details of the individual design steps have been described in } \\
\text { previous publications and the objective of this paper is to focus on how the components of the control system designed at } \\
\text { each step integrate into the overall IFPC system. The full nonlinear IFPC system was evaluated extensively in nonreal- } \\
\text { time simulations as well as piloted simulations. Results from the nonreal-time evaluations are presented in this paper. } \\
\text { Lessons learned from this application study are summarized in terms of areas of potential improvements in the STOVL } \\
\text { IFPC design as well as identification of technology development areas to enhance the applicability of the proposed design } \\
\text { methodology. }\end{array}$} \\
\hline \multirow{2}{*}{\multicolumn{4}{|c|}{$\begin{array}{l}\text { 14. SUBJECT TERMS } \\
\text { Integrated control; Flight control; Propulsion control; STOVL aircraft; Centralized control; } \\
\text { Decentralized control }\end{array}$}} & $\begin{array}{c}\text { 15. NUMBER OF PAGES } \\
17\end{array}$ \\
\hline & & & & $\begin{array}{r}\text { 16. PRICE CODE } \\
\text { A03 }\end{array}$ \\
\hline $\begin{array}{l}\text { 17. SECURITY CLASSIFICATION } \\
\text { OF REPORT } \\
\text { Unclassified }\end{array}$ & $\begin{array}{l}\text { 18. SECURITY CLASSIFICATION } \\
\text { OF THIS PAGE } \\
\text { Unclassified }\end{array}$ & $\begin{array}{l}\text { 19. SEC } \\
\text { OF }\end{array}$ & ATION & 20. LIMITATION OF ABSTRACT \\
\hline
\end{tabular}

NSN 7540-01-280-5500 